\title{
INFLUÊNCIA DA REDE PEA-UNESCO NA IMPLANTAÇÃO DE PROGRAMAS DE EDUCAÇÃO PARA SUSTENTABILIDADE EM ESCOLAS PARCEIRAS
}

Carla Szazi Marum ${ }^{1}$

Diego de Melo Conti²

Luiz Fostinone Netto ${ }^{3}$

Carlos Nabil Ghobril ${ }^{4}$

Silton Marcell Romboli ${ }^{5}$

Resumo: A educação para a sustentabilidade é uma das soluções para a transformação do planeta e da sociedade. Este artigo trata da análise do "Programa de Escolas Associadas" (PEA) das Nações Unidas para a Educação, a Ciência e a Cultura (UNESCO) e analisa a sua influência para a educação para a sustentabilidade. Esta rede tem como propósito fomentar os valores e os princípios de sustentabilidade na educação em todos os Estados membros da ONU. Para a construção deste trabalho foi realizada uma pesquisa qualitativa, com base em uma literatura, pesquisa documental, entrevistas com atores-chave, resultando na construção de dois estudos comparados baseados em escolas de educação básica da rede pública e particular associadas à Rede PEA localizadas no Estado de São Paulo - Brasil.

Palavras-chave: Educação; Sustentabilidade; UNESCO; Rede PEA.

${ }^{1}$ Fundação Instituto de Administração (FIA). E-mail: carla_marum@hotmail.com

2 Pontifícia Universidade Católica de São Paulo (PUC-SP). E-mail: diegoconti@uol.com.br

${ }^{3}$ Pontifícia Universidade Católica de São Paulo (PUC-SP). E-mail: luiz.f.netto@hotmail.com

4 Instituto de Economia Agrícola (IEA). E-mail: ghobril@gmail.com

${ }^{5}$ Universidade Municipal de São Caetano do Sul (USCS). E-mail: silton.romboli@uscs.edu.br 


\section{Introdução}

O Programa de Escolas Associadas (PEA) da UNESCO foi lançado em 1953, com a finalidade de fortalecer o papel da educação escolar na promoção da cultura de paz, respeito à diversidade cultural, desenvolvimento sustentável, cooperação internacional e valores democráticos em todos os países membros da ONU. Os objetivos do Programa se expandiram nas últimas décadas no intuito de atender às novas demandas da escola e da sociedade em tempos de globalização e aprofundamento de problemas globais, tais como desigualdade social, degradação do meio ambiente, exclusão, racismo, fome, desemprego e analfabetismo.

Atualmente, o PEA tem como meta fundamental encorajar as escolas associadas a oferecer um tipo de educação de qualidade que promova inclusão e justiça social e eduque cidadãos responsáveis e conscientes de seu papel tanto na comunidade local como global. Essa educação de qualidade se baseia essencialmente nos quatro pilares de educação da UNESCO (DELLORS, 2010): aprender a ser, aprender a aprender, aprender a fazer e aprender a conviver juntos. O PEA tem ainda por objetivo contribuir para o alcance das oito metas do Milênio (PNUD, 2000) e das seis metas de Educação para Todos (DACAR, 2000) até o ano de 2015.

Espera-se que uma escola PEA deva procurar meios inovadores e criativos para tornar o currículo e aprendizagem escolar mais dinâmica e próxima da realidade dos alunos. Além de recomendar que a escola trabalhe com temas do cotidiano escolar, o programa orienta que as escolas associadas desenvolvam atividades relacionadas com as seguintes temáticas centrais: a) problemas mundiais e o papel da ONU, b) direitos humanos, democracia e tolerância, c) aprendizagem intercultural, d) meio ambiente e desenvolvimento sustentável. O programa também sugere que a escolas associadas desenvolvam trabalhos relacionados com datas comemorativas e anos internacionais adotados pela ONU.

O objetivo deste trabalho é investigar a influência que a rede PEA exerce sobre as escolas parceiras na implantação de programas em Educação para a Sustentabilidade e, por isso buscou responder a seguinte pergunta de pesquisa: qual é o impacto e as mudanças promovidas pela Rede PEA nas escolas parceiras no processo de implantação da educação para a sustentabilidade? Ainda, o artigo apresenta uma análise profunda de uma pesquisa realizada em duas escolas associadas à rede PEA de Educação Básica, localizadas no Estado de São Paulo (SP).

\section{Organismos internacionais e sua influência na educação brasileira}

Os organismos internacionais surgiram de modo marcante e abrangente após os grandes conflitos que marcaram o século $X X$ e que levaram a comunidade internacional a criar formas de superar os conflitos de forma dialogada bem como responder a problemas globais que os Estados, de forma isolada, não conseguiriam resolver.

revista brasileira educação ambiental 
A ONU (Organização das Nações Unidas), que foi criada em 24 de outubro de 1945, e a UNESCO em 16 de novembro de 1945, surgem quase concomitantemente num período pós-guerra, em Londres, com a presença de representantes de 37 países para assinar a Constituição que em seu preâmbulo proclama "Já que as guerras nascem na mente dos homens, é na mente dos homens que devemos erguer os baluartes da paz.", com o objetivo de garantir a paz por meio da cooperação intelectual entre as nações, acompanhando o desenvolvimento mundial e auxiliando os Estados-Membrosatualmente são 193 países- na busca de soluções para os problemas que desafiam nossa sociedade (UNESCO, 2015)

A representação da UNESCO no Brasil foi estabelecida em 1964 e seu Escritório, em Brasília, iniciou as atividades em 1972, tendo sempre como foco a relevância da educação como valor estratégico para o desenvolvimento social e econômico dos país. Prioriza a defesa de uma educação de qualidade para todos e a promoção do desenvolvimento humano e social. Para isso, a organização desenvolve projetos de cooperação técnica em parceria com o governo - União, estados e municípios -, a sociedade civil e a iniciativa privada, além de auxiliar na formulação de políticas públicas que estejam em sintonia com as metas acordadas entre os Estados Membros da Organização.

Em um encontro de cúpula realizado em Johanesburgo em 2002 os membros participantes recomendaram à Assembleia Geral da ONU, que promulgasse a "Década da Educação para o Desenvolvimento Sustentável (2005 - 2014)", que por sua vez atribuiu à UNESCO a tarefa de desenvolver propostas para programar ações nesta direção.

Basicamente as propostas da UNESCO se resumem em quatro pontos contidos no documento "United Nations Decade of Education for Sustainable Development (2005-2014) Framework for the International Implementation Scheme" (UNESCO, 2006, p.4-5), sendo elas: 1) Promoção e melhoria da educação básica; 2) Reorientar os programas educacionais existentes; 3) Desenvolver $o$ entendimento e a consciência das pessoas sobre a sustentabilidade e 4) Capacitar os trabalhadores de todos os setores para que tenham conhecimento e habilidades para desenvolverem seu trabalho de maneira sustentável.

Nesse contexto, surge a rede PEA (Programa das Escolas Associadas) como um braço da UNESCO ligada diretamente à educação. Foi criada para estender os objetivos dessa organização mundial, no pós-guerra. Além dos objetivos já expostos, os compromissos do programa se expandiram nas últimas décadas no intuito de atender às novas demandas da sociedade em tempos de globalização, tais como a desigualdade social, a degradação do meio ambiente, a exclusão, o racismo, a fome, o desemprego e o analfabetismo (PEA-UNESCO, 2014)

A UNESCO não dispõe de recursos financeiros para as escolas associadas, no entanto recomenda que toda escola PEA faça contatos e parcerias com outras escolas associadas, organizações e instituições públicas 
ou privadas, tanto no nível regional como nacional e internacional. Essas parcerias devem ser feitas no sentido de criar alternativas para garantir 0 suporte financeiro, pedagógico e tecnológico necessário. Toda escola PEA necessita também elaborar e encaminhar relatórios anuais de atividades realizadas para a coordenação regional e/ou nacional das escolas associadas da UNESCO.

A Rede está presente em 180 países e o Brasil é um dos países signatários da criação do PEA com o maior número de escolas associadas. Em todo o mundo são quase 9.600 escolas associadas sendo que destas, 29\% estão presentes na Europa e América do Norte, 22\% na América Latina e Caribe, $21 \%$ na África, $10 \%$ nos Países Árabes e 18\% na Ásia e Pacífico. (Revista PEA, 2014). Trata-se de um programa vital para o fomento do desenvolvimento sustentável, sensibilizando e conscientizando as gerações do presente para a construção de um futuro melhor.

\section{Metodologia}

As principais fontes de pesquisa utilizadas neste trabalho foram os diversos documentos produzidos pela UNESCO e em conjunto com órgãos multilaterais. Estes documentos oficiais sejam eles relatórios, declarações ou tratados diversos, acabam delimitando os princípios e posicionamentos deste organismo. A análise documental favorece a observação do processo de maturação ou de evolução de indivíduos, grupos, conceitos, conhecimentos, comportamentos, mentalidades, práticas, entre outros (CELLARD, 2008)

Para a realização da pesquisa de campo optou-se pelo método qualitativo. Para isso foi utilizado como instrumento a realização de um estudo comparativo entre duas escolas - uma pública e uma privada - da rede PEA. Apesar deste estudo limitar-se à análise de duas escolas associadas do Estado de São Paulo, os dados coletados são representativos, o que permite traçar um perfil de como o PEA vem exercendo influência na construção de uma educação para a sustentabilidade no Brasil.

Os dados da pesquisa foram coletados por meio de entrevistas semiestruturadas. Também foi realizado um encontro com a coordenadora regional do PEA em São Paulo para que fossem elencados temas, perguntas relevantes e materiais para a introdução da construção de questionários e fontes de pesquisa além da análise do currículo e proposta pedagógica das escolas. As entrevistas foram realizadas entre julho e agosto de 2015, gravadas e transcritas para melhor comparação e análise dos resultados.

\section{Objetos e sujeitos da pesquisa}

Para a realização dos estudos de caso foram escolhidas duas escolas associadas à rede. Ambas do Estado de São Paulo, uma da rede privada de ensino, outra da rede pública municipal. Procurou-se escolher escolas de perfis parecidos quanto ao número de alunos, cursos oferecidos e estrutura física. Foram entrevistados oito membros da comunidade escolar, sendo eles

revista brasileira educação ambiental 
diretores, professores e alunos do segundo ano do Ensino Médio. Por razões éticas, os nomes das escolas investigadas e entrevistados serão mantidos em sigilo no documento da pesquisa, as quais serão chamadas de "escola A" e "escola B".

A escola $A$ pertence à rede pública do ensino municipal da cidade de São de Caetano do Sul e tem 47 anos de existência. Possui cerca de 2000 alunos matriculados, que se dividem em Ensino Fundamental I e II, Ensino Médio e Ensino Profissionalizante. Os diretores são sempre nomeados pelo prefeito municipal com uma gestão de quatro anos. Em 2000 recebeu o selo e a permissão de uso em documentos oficiais como "Escola Associada à UNESCO", pelo desenvolvimento de projetos com ênfase no protagonismo juvenil e voluntariado. A escola possui quadras, campo, laboratórios, assistência aos alunos e várias atividades para que 0 aluno consiga se desenvolver. De acordo com a nota do Exame Nacional do Ensino Médio 2010 (Enem), a escola $A$ é a melhor instituição de ensino público e não técnica do Estado de São Paulo. A média obtida pela instituição foi de 618,27, um valor acima da média geral obtida pelos estudantes de toda a rede pública do Estado, que foi de 511,21, segundo o Ministério da Educação (MEC).

A escola $B$, da rede privada de ensino, localiza-se em bairro nobre da cidade de São Paulo. Com quase 40 anos de existência, a escola atende em torno de 1500 alunos desde a Educação Infantil ao Ensino Médio. A direção da escola mantém-se a mesma desde a sua fundação. Foi à primeira escola a associar-se a rede PEA no Estado de São Paulo. A escola está instalada em ampla área de $12.799 \mathrm{~m} 2$, com duas unidades contíguas com espaços diferenciados: laboratórios, quadras, bibliotecas, ateliê de artes, salas de multimídia entre outros. De acordo com a nota do Exame Nacional do Ensino Médio 2010 (Enem), esta escola obteve em 2010, a média de 687,19 pontos.

\section{Análise dos resultados}

O método escolhido e a construção de dois estudos de casos comparados permitiu um maior aprofundamento da Rede PEA e da realidade dos objetos pesquisados. A análise realizada mostra um resultado satisfatório para os objetivos deste artigo, mas que não é passível de generalizações a todas as escolas associadas.

A escola A, que apesar de pré-agendada, os entrevistados mostraramse desorganizados e pouco colaborativos, não demonstrando interesse pela seriedade da pesquisa. Apesar disto, todas as entrevistas propostas foram realizadas seguindo os critérios de conformidade pré-estabelecidos. $O$ mesmo não ocorreu na escola B. Nesta os participantes da pesquisa mostraram-se solícitos e participativos.

Após visitar as duas escolas e entrevistar professores, alunos e gestores constata-se que o impacto educacional e social do PEA é ainda parcialmente limitado, principalmente na escola $A$ investigada uma vez que os alunos, 
professor e gestor apresentam considerável desconhecimento em relação aos pilares, objetivos e abrangência do programa.

Durante as entrevistas ao perguntar sobre o PEA, a maior parte dos entrevistados não sabia o que era e nem o que significava ser associado à rede. Ao explicar resumidamente o significado da sigla (Programa das Escolas Associadas a UNESCO), sabiam que a escola era associada a UNESCO. Ou seja, desconhecem o termo PEA embora reconheçam que a escola é associada a UNESCO, mesmo não entendendo claramente o significado disto. A título de exemplo, destacam-se três trechos das entrevistas da escola A:

[...]A escola é associada à cerca de 15 anos. Foi uma das primeiras escolas públicas a conseguir o selo. Foi conseguido através de ações que a escola já realizava como as ações solidárias. O" Faça Parte" coisas que existiam desde a época do Fernando Henrique (ex-presidente da República). A escola já vinha trabalhando focado nos parâmetros da UNESCO. Após ter conseguido o selo, isso virou uma rotina dentro da escola. Esse ano (2015), por exemplo, sabemos que é o ano da luz. Daí, automaticamente, no início do ano, essa informação já é passada, discutida e estudada pelos professores e automaticamente diversas atividades dentro desse segmento vão ser realizadas. Para a comunidade ser associado é muito abstrato isso, para os professores, funcionários e alunos. Não tem a dimensão exatamente do que isso significa, do retorno, da relação custo benefício (Escola $A$, gestor)

[...] Eu entrei aqui com 6 anos, no $1^{\circ}$ ano. Já tô aqui há muito tempo. O PEA eu não sei não... conheço que a escola é associada da UNESCO, de todo mundo falar e de ver o logo da UNESCO na entrada... mas nunca pesquisei, estudei mais. Eu sei que a UNESCO é da ONU e que é sobre educação e que todo ano tem um tema que a escola trabalha e não sei muito mais não. Sei que ela tem vários projetos voltados para e educação e sobre sustentabilidade, essas coisas... (Escola A, aluno 1)

[...] Eu estudo aqui há 7 anos. Entrei a partir do 60 ano. Quando eu entrei, eu não sabia que a escola era associada a UNESCO. Mas depois teve várias festas, eventos, que falavam disso. Aí depois de um ou dois anos eu já sabia e me informei sobre isso. Mas eu não sei bem o que é isso. Eu acho porque as pessoas nem sabem o que é a UNESCO e as pessoas vão se informando e tem alguns que até vão em busca de mais informações, até mais do que as que a escola dá e eu acho muito importante até prá você ter mais conhecimento sobre o assunto. (Escola A, aluno 2) 
Fica claro, através das colocações feitas pelos entrevistados, que a informação e conhecimento sobre a rede PEA e o que ela propõe vão se dissipando dentro da hierarquia desta escola. No entanto, os alunos, os quais deveriam ser os principais beneficiados e objeto final de todo os trabalhos propostos apresentam desconhecimento sobre a rede.

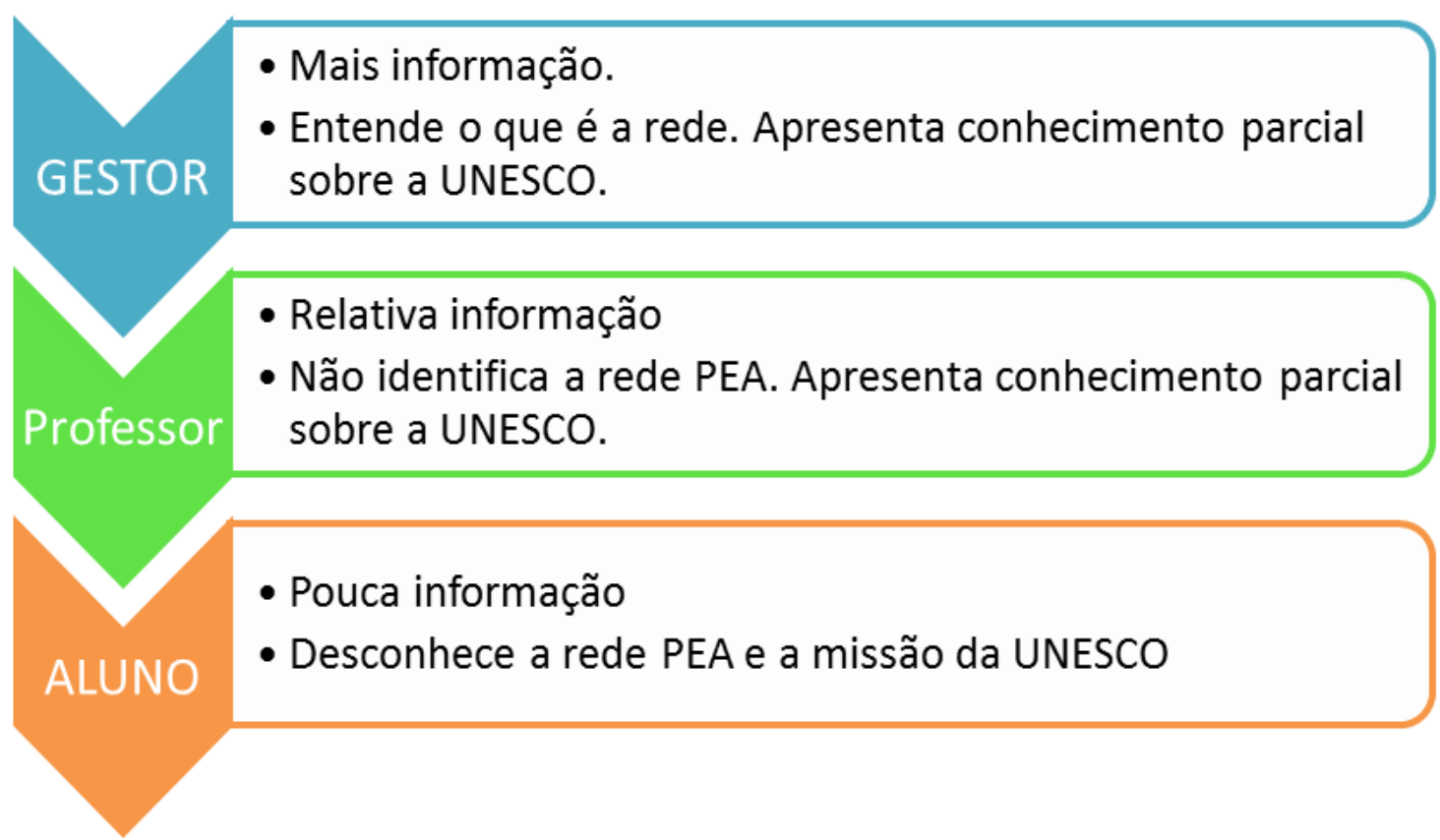

Figura 1: Conhecimento sobre o significado da rede PEA na escola $A$

Fonte: Autoria própria.

$\mathrm{Na}$ escola $\mathrm{B}$, no entanto, percebemos uma melhora significativa quanto ao conhecimento do significado da escola ser associada. Os entrevistados (gestor e professor), com maior nível de informação sobre o PEA, entendem o programa como uma iniciativa internacional da UNESCO de grande importância que além de trabalhar com as questões de valores, reforça a dimensão humana da educação e melhora a qualidade do ensino na escola. $O$ gestor apresenta uma amplitude consideravelmente maior em relação aos pressupostos da rede. Já o professor acentua a presença dos Anos Internacionais como foco maior de trabalho desconhecendo ou apresentando pouco conhecimento sobre a totalidade e significação da rede. $O$ gráfico número 1 também se insere na realidade da escola $B$, embora em outra dimensão, pois através dos relatos nota-se também uma perda significativa de informações e entendimento a respeito da rede mesmo que apresentem maior nível de informação conforme trechos das entrevistas relatados a seguir. 
[...] Desde o início a escola é associada à rede 1983/84 embora a rede ainda não existisse no Brasil. Nós na época recebíamos material do PNUD que é um braço da ONU e da UNESCO. No início a preocupação era da implementação da escola propriamente dita, mas já inserimos dentro do currículo todos os valores que compõe a rede. A rede PEA é uma rede comprometida com a qualidade do ensino, essa é a grande preocupação e por isso foi criada pra que não se incorresse em erros na formação de carácteres que viessem a produzir a exterminação humana, pelo viés da paz, não só pelo sinônimo de não guerra, mas como sinônimo, sobretudo de uma consciência e de um respeito à vida. Então veja, todo o currículo da escola então foi transversalizado. Nós fomos transversalizando, ou seja, todo assunto você carregava de fatos dentro dos princípios e conceitos, esses que nós temos obrigação de ensinar, vinham os valores das atitudes e as normas. Os valores, atitudes e normas vinham amalgamado aos fatos, princípios e conceitos que formam o currículo da escola, então a preocupação não era nós dizermos que éramos da rede PEA. Isso foi vindo aos poucos e nós não tínhamos ainda os fundamentos do trabalho nem o PEA no Brasil que era ainda um ilustre desconhecido. (Escola B, gestor)

[...] Eu trabalho aqui há 25 anos. Não me lembro bem mas há muito tempo a escola tem participado no PEA e dos Anos Internacionais. Os Anos internacionais permitem esse trabalho nas várias disciplinas. Às vezes a coisa fica mais no teórico. $\mathrm{O}$ fato de a escola ser associada vem sendo construído. No início o número de professores engajados era muito pequeno. À medida que o tempo foi passando o envolvimento foi aumentando. Passou também a ser uma exigência do colégio. Os orientadores, toda vez que vão montar o planejamento com os professores, tem a preocupação de inserir as preocupações desses anos internacionais, dos conteúdos que os professores vão trabalhar. Hoje a totalidade dos professores trabalham, alguns com mais intensidade, porque virou uma prática e se tornou obrigatório trabalhar esses Anos Internacionais. (Escola $\mathrm{B}$, professor)

[...] Eu estudo aqui desde o Ensino Fundamental I. Há 11 anos. Eu não conheço a Rede PEA, não... não, conheço a rede PEA. Sei que o colégio é associado a UNESCO. Já comentaram bastante sobre a escola ser associada a UNESCO. Eu acho que é assim... Quando o assunto é relacionado aos alunos à isso (PEA), os professores se envolvem muito com a gente. Ahn... na verdade, saber exatamente o que a UNESCO faz não sabemos, mas nós compreendemos que fazemos muitas atividades que estão relacionadas a isso.... Mas o que significa ser uma escola associada da UNESCO, não. De verdade, não. (Escola B, aluna 1) 
[...]A rede PEA eu não conheço, mas a escola faz muitos trabalhos e eles estão sempre falando que estão exercendo papéis assim..ahn, que a UNESCO propõe. Tipo todos os Anos Internacionais a gente participa, ficam sempre falando de outras escolas que também participam, e que também ajudam nos projetos da UNESCO. Então sim, eu conheço. (Escola B, aluna 2)

Apesar de identificar grandes diferenças no contexto das escolas investigadas, ao analisar o projeto pedagógico, a escola $A$ não menciona os quatro pilares da educação adotados pela UNESCO (aprender a ser, aprender a fazer, aprender a aprender e aprender a conviver juntos) que devem nortear a prática educativa de uma escola PEA rumo à promoção da educação de qualidade. No entanto percebe-se, através dos relatos, uma forte preocupação com uma educação diferenciada e de referência na região. Mostram-se orgulhosos em ser a única escola na cidade que possui o selo de escola associada a UNESCO. Possuem vários projetos relacionados à formação cidadãos quais evidenciam esta preocupação, entre eles:

- Gincana Solidária que envolve toda a comunidade escolar ao longo do ano letivo com o intuito de arrecadar alimentos e outros bens consumíveis objetivando a doação a entidades sociais da região. Os alunos, além de colaborarem com a arrecadação, participam do processo de seleção das entidades e entrega dos produtos com a realização de vivências junto a estas entidades.

- Videoconferência reúne escolas e alunos de vários países (Canadá, México, Brasil, Rússia, EUA, etc.), que discutem temas relacionados ao bem estar mundial. Esses temas são, geralmente, aqueles que afligem vários países como: água, poluição, meio ambiente, biodiversidade, etc.

- Projeto Interdisciplinar em que, no decorrer do ano letivo, os alunos realizam pesquisas sobre temas, desenvolvem trabalhos e, no mês de novembro de cada ano, apresentam em feiras e gincanas.

Através da realização destes projetos percebe-se a preocupação da escola $A$ em formar o seu aluno integralmente oferecendo-lhe a possibilidade de entrar em contato com problemas globais, desenvolver o senso crítico e humanitário mesmo que não nomeados conforme o que uma escola PEA propõe.

Através dos relatos, observações e análise documental fica clara a intencionalidade da realização de um trabalho diferenciado, porém sem tê-los de forma estruturada com objetivos definidos e metas a serem atingidas. Com exceção da Gincana Solidária que envolve obrigatoriamente toda a comunidade escolar observa-se que, a maior parte dos projetos citados ocorre de forma voluntária abarcando apenas uma minoria de alunos.

Já na escola B esta informação aparece de forma mais precisa no site da escola e nos documentos internos, como planos anuais que definem, em 
cada série, qual temática será abordada, dentro de um crescente, envolvendo nitidamente os pilares propostos pela UNESCO.

Apesar disto, em relação às quatro temáticas do programa, constatamos que as questões voltadas para problemas mundiais, direitos humanos, democracia, tolerância e aprendizagem intercultural ocupam espaço mais limitado dentro das atividades da escola $A$, onde o maior destaque está relacionado aos Anos Internacionais propostos pela ONU e que a maioria dos entrevistados não apresenta um conhecimento específico em relação às outras temáticas sugeridas pelo programa.

Este fato é percebido principalmente na fala dos entrevistados nas quais se observa comentários e referências apenas aos Anos Internacionais:

Deve-se levar em conta que os projetos PEA-UNESCO têm caráter multidisciplinar e que os Anos Internacionais proclamados pela ONU servem para mobilizar ações de apoio às questões de interesse internacional focalizando as necessidades emergentes da humanidade.

$O$ aluno 2 da escola $A$, relembra o trabalho realizado sobre o Ano Internacional da Água cujo foco de trabalho foi o estudo da Represa Billings que fica próxima a sua escola. Além da pesquisa feita sobre dados históricos, problemas enfrentados, situação atual, abastecimento e poluição da água, entrevistaram também pessoas que moram no entorno da represa.

$\mathrm{Na}$ escola $\mathrm{B}$ situação parecida foi relatada pelo Aluno 2 também referente ao Ano Internacional da Água, conforme transcrições que se seguem:

[...]Dentre os projetos, um que eu me lembro bem e que eu tô mais familiarizada, que eu me envolvi muito, mas muito mesmo, foi o projeto "Agua é vida", desenvolvido no ano passado. Foi um projeto que nós tínhamos que pesquisar sobre um rio que estava poluído bem do lado da nossa escola e foi um projeto que também foi ligado a UNESCO, foi um projeto completamente diferente porque nós não tínhamos apenas que pesquisar sobre as condições da água... Nós realmente fomos lá, falamos com os moradores perto de lá, criamos estatísticas, nós vimos o que aconteceu de perto, e isso fez com que a gente fixasse muito mais a experiência, mesmo! Então a gente não faz apenas pesquisas, gráficos e tabelas, mas nós vamos até lá, nós tentamos resolver, nós damos uma solução. $E$ eu acho que é esse o diferencial que a UNESCO dá para a escola e nos dá de volta também.

[...]Eu lembro que teve um projeto que teve ligação com a água e que tem um córrego que é perto da minha escola, na rua da escola e ele é a céu aberto e que virou um esgoto a céu aberto. A escola fez um projeto que a gente teve que fazer várias pesquisas com moradores da rua, como era entes dele ser esgoto, e aí a gente fez e pegou esse trabalho e mandou para a subprefeitura do município de SP e depois esse estudo foi transformado num livro que os alunos mesmo apresentaram e 
eu fiz o projeto de fotografia e pesquisa. Isso foi uma coisa muito legal porque todos os anos a gente faz um projeto. $O$ projeto da subprefeitura era para canalizar o córrego só que até agora não tinha canalizado, mas a escola tá até agora esperando para que façam alguma coisa porque você passa ali na frente e incomoda demais, o cheiro, as pessoas se incomodam demais...

Este relato mostra que, quando os Anos Internacionais são bem trabalhados, dentro das escolas, eles atendem de forma transversal aos quatro pilares bem como às demais temáticas que ficam implícitas dentro do tema, conforme se verifica no quadro 1 .

Tabela 1: Relação entre projetos das escolas e pilares do PEA

\begin{tabular}{|c|c|c|c|}
\hline & Objetivo Atendido & Escola A & Escola B \\
\hline Aprender a ser & $\begin{array}{l}\text { Espírito crítico, } \\
\text { mobilizador e } \\
\text { transformador. }\end{array}$ & $\begin{array}{l}\text { Desenvolvidos ao longo } \\
\text { de todo o projeto. }\end{array}$ & $\begin{array}{c}\text { Desenvolvidos ao longo } \\
\text { de todo o projeto. }\end{array}$ \\
\hline $\begin{array}{l}\text { Aprender a } \\
\text { conviver }\end{array}$ & $\begin{array}{l}\text { Percepção de } \\
\text { interdependência, } \\
\text { identidade própria e } \\
\text { respeito ao próximo. }\end{array}$ & $\begin{array}{c}\text { Entrevista com a } \\
\text { comunidade do entorno e } \\
\text { percepção dos } \\
\text { problemas locais. } \\
\text { Realização do trabalho } \\
\text { em grupo. }\end{array}$ & $\begin{array}{c}\text { Entrevista com a } \\
\text { comunidade do entorno } \\
\text { e percepção dos } \\
\text { problemas locais. } \\
\text { Realização do trabalho } \\
\text { em grupo. }\end{array}$ \\
\hline $\begin{array}{l}\text { Aprender a } \\
\text { conhecer }\end{array}$ & $\begin{array}{c}\text { Consciência dos } \\
\text { problemas mundiais e } \\
\text { locais, ações extramuros } \\
\text { escolares. }\end{array}$ & $\begin{array}{l}\text { Levantamento de dados, } \\
\text { entrevistas, pesquisas } \\
\text { multifocais e de campo a } \\
\text { respeito do tema. }\end{array}$ & $\begin{array}{l}\text { Levantamento de dados, } \\
\text { entrevistas, pesquisas } \\
\text { multifocais e de campo a } \\
\text { respeito do tema. }\end{array}$ \\
\hline Aprender a fazer & $\begin{array}{l}\text { Aprendizagem proativa, } \\
\text { pesquisa, análise, } \\
\text { conclusão e resolução de } \\
\text { problemas. }\end{array}$ & $\begin{array}{l}\text { Elaboração de projetos } \\
\text { evidenciando soluções, } \\
\text { elaboração de abaixo } \\
\text { assinado enviado ao } \\
\text { Secretário do Meio } \\
\text { Ambiente solicitando a } \\
\text { despoluição da represa. }\end{array}$ & $\begin{array}{l}\text { Elaboração de projetos } \\
\text { evidenciando soluções e } \\
\text { de solicitação de } \\
\text { canalização do córrego à } \\
\text { subprefeitura da cidade. }\end{array}$ \\
\hline
\end{tabular}

Fonte: Autoria própria.

Os dados colhidos nestas escolas, em contextos tão diferenciados e distantes uma da outra, reforça a influência que pode ser exercida pela UNESCO-PEA dentro das escolas a partir do momento em que gestores e professores desenvolvem projetos interdisciplinares que envolvam um olhar criterioso para os problemas do entorno a qual a escola pertence.

A Década da Educação para o Desenvolvimento Sustentável- 2005-2014 é o passo mais recente da ONU de apoiar tanto a educação quanto o desenvolvimento sustentável entendendo que chegar a um, só é possível, através do outro.

Apesar de todo o esforço da UNESCO e rede PEA nesta área, percebese através deste estudo comparativo, que há ainda um longo caminho a trilhar. 
A palavra sustentabilidade ou Educação para a Sustentabilidade não aparecem no currículo e proposta pedagógica de forma clara em nenhuma das escolas analisadas bem como no discurso dos participantes, embora se perceba a existência de vários projetos ou atividades pedagógicas relacionadas à temática do meio ambiente.

$\mathrm{Na}$ escola há uma forte tendência entre os relatos dos entrevistados que educação para a sustentabilidade é representada através de práticas envolvendo basicamente a realização de coleta seletiva, economia de água, energia e outros bem consumíveis, ter contato com a natureza e ter uma horta na escola. Tanto o gestor quanto o professor veem ainda o conceito de sustentabilidade ligado à infraestrutura da escola. Ela acontece através de ações dentro do universo da escola, a saber:

[...] Isso tá bem distante da gente porque eu acredito que uma escola sustentável seria uma que tivesse toda infraestrutura adequada para promover a sustentabilidade tipo reciclagem, reuso da água e uma série de parâmetros estruturais que a gente não tem. $E$ fora isso, fosse uma escola na qual também a sustentabilidade estivesse à frente de todas as decisões, por exemplo, quantas cópias você vai fazer de uma prova, mas que evite o desperdício, isso é bem modesto, pra ser realmente uma escola sustentável. (Escola A, gestor)

[...] Nós realizamos vários projetos para a sustentabilidade. A gente tem a horta, a gente tem a reciclagem, ali tem uma lata enorme pra recolher lata... No ano passado fizemos uma campanha para recolher eletrônico, sucatas, e nas salas do ano passado a gente tinha uma caixa bem grande para a reciclagem de papel. Estamos tentando recolher garrafa pet, mas a gente precisa de espaço e a gente não têm. A gente vende o material e a renda vai para APM (Associação de Pais e Mestres) da escola pra melhorias da escola. Tem também a Escola de Ecologia aqui do lado que serve tanto pra parte da jardinagem da cidade e ali tem todo o processo. Eles fazem as mudas, adubo, refazem a jardinagem da cidade, além de terem um projeto educativo que tem a parte de jardinagem, as crianças entram em contato com diversos tipos de plantas. (Escola A, professor)

Já os alunos entrevistados, em ambas as escolas, conseguem ampliar um pouco mais esta visão acrescentando maior participação e sugerindo uma educação mais proativa e coerente. Abaixo trechos das entrevistas que relatam esta situação.

[...] Eu acho que uma escola sustentável tem que ser uma que não só fale, tem que ser uma que mostre que você também pode ajudar. Tipo a água, ele tem que fazer parte do problema. 
Tipo tem escola que tem goteira e não concerta, não tem que só falar que tem economizar água, tem que mostrar que se preocupa (a escola) para ser exemplo pra quem tá vendo. A escola tem que ser exemplo para os alunos. Não seria só a direção. Seriam todos envolvidos, professores, alunos, funcionários, etc. Seriam todos envolvidos em querer tornar a escola melhor e mais sustentável. Teria que ter uma estrutura para os alunos desenvolverem o que eles pensam de sustentabilidade. Uma horta na escola, questões de saúde. A água, como economizar, ter medidor de torneira, sei lá, algo que mostrasse o desperdício, sensores de luz e água. Todo mundo ajudava, participava...os alunos fossem mais conscientes e os professores ajudassem a conscientizar, onde meio que todo mundo se envolvesse de igual para igual. (Escola A, aluno 2)

[...] Eu acho que vou fazer a situação inversa, eu vou contar porque eu acho importante... Eu acho que... De acordo com o que a gente vive, assim, ahn... A situação que a gente está é só bastar, parar e olhar em volta. Enfim, e ver o que não tá certo e ver que é necessário essa educação. Que aquilo que eu falei antes que é restaurar aquilo que está perdido e preservar aquilo que a gente já tem. Então eu acho que essa é a importância dela (educação para a sustentabilidade) e que eu não sei exatamente, sendo bem sincera, como seria a melhor forma de educar para alguém o que é sustentabilidade, como preservar, como praticar a sustentabilidade. Mas eu acho que isso passa muito pela convivência, porque a gente nunca conhece os problemas, de verdade, até a gente enfrentá-los. Então pra mim seria a partir de idas assim, e ver exatamente o que está acontecendo com o local, ou com alguma certa área. Eu acho que seria mais isso, porque a gente não imagina quão problemático pode ser até conhecer na pele. (Escola $B$, aluno 1)

[...] Acho que uma escola sustentável precisa ter que conscientizar os alunos sobre o que tá acontecendo e mesmo que não estiver acontecendo, deve conscientizar sobre o que não deve acontecer. Além de ter que mostrar que como deve se fazer para que cada parte desses três o que deve fazer pra funcionar. Vamos supor, na parte ecológica, tem que fazer o negócio da reciclagem, tem que plantar mais, tem que conservar a natureza, a parte social sempre tem que tentar trabalhar não só por você, mas também pelos outros, e viver numa sociedade sem conflitos, e na parte econômica tem que saber que não dá para desenvolver a qualquer custo porque tem essa coisa assim de dinheiro e querer sempre mais sabe? Países ricos e países pobres, escravidão, miséria... Isso não é nada sustentável! (Escola B, aluno 2) 
Estes alunos reconhecem a importância da Educação para Sustentabilidade (EDS) e apontam como caminho uma educação mais vivencial, que extrapole os muros da escola para que possam conhecer outras realidades e intervir nelas. Saem um pouco da visão apenas ambiental e entendem que a parte social/humana também tem um peso muito grande para um mundo sustentável.

Quando questionados sobre a contribuição da rede para a sua formação cidadã, todos os alunos afirmaram que a UNESCO contribui bastante embora não consigam mensurar ou exemplificar esta importância e, em alguns momentos inclusive, atribuindo ações realizadas na escola como ações da UNESCO. Há uma confusão entre espaços e ações que são da escola com espaços relacionados à UNESCO. Como por exemplo, o benefício da cisterna na escola A. O aluno acreditava que a UNESCO quem a doou. Sabe-se que a rede PEA não contribui financeiramente com nenhuma escola associada e nem fornece materiais deste tipo.

Os professores também reconhecem o PEA como um ganho importante em qualidade de ensino. Acreditam que os materiais enviados e disponibilizados no site acabam por influenciar e direcionar muitos projetos que acontecem na escola. Apesar disto, não percebem a rede dentro da escola. Entendem que é mais uma atitude da própria escola de ir à busca de suas necessidades.

$\mathrm{Na}$ Escola $\mathrm{A}$ há um consenso entre gestor, professor e aluno que a rede contribui para a formação de visão de mundo do aluno embora não a relacionem com EDS. Há uma contradição em suas falas o que demonstra a grande falta de conhecimento a respeito do que é uma educação para a sustentabilidade. Reconhecem a importância embora, através de seus relatos, é algo muito mais intrínseco ao perfil da escola do que ao papel que a rede oferece.

[...] A gente não vê uma interferência direta deles aqui na escola tanto na parte cultural quanto na parte conceitual é mais a gente que acaba buscando coisas do que eles trazendo coisas pra nós. Não tem uma influência tão grande, direta nesse sentido. É muito abstrato isso, para os professores funcionários e alunos. Não tem a dimensão exatamente do que isso significa, do retorno, da relação custo benefício, mas nós sabemos que a UNESCO estabelece alguns princípios que nós procuramos seguir. (Escola $A$, professor)

$\mathrm{Na}$ escola $\mathrm{B}$, no entanto, há um aprofundamento maior e entendimento mais amplo sobre construção da cidadania, visão de mundo e educação para a sustentabilidade atribuindo a UNESCO, grande contribuição. Este reconhecimento está presente nos relatos de todos os entrevistados. Há uma discussão maior dentro da escola para entender o papel da rede. 
[...] Essa questão da sustentabilidade passou a ser mais discutida depois que a escola passou a fazer parte da rede. Antes eu acho que era isolado. Eram projetos pontuais. Esse trabalho permite reflexões e isso é importante para a formação do aluno. De imediato a gente não vê resultados práticos, mas a gente sabe que está contribuindo para a formação da cidadania. Por exemplo, ao longo dos anos venho percebendo uma diminuição em relação a preconceito, diferenças culturais que vão mudando no aluno, no posicionamento dele. Trabalhando o que o PEA propõe a gente percebe essa mudança, mas a maioria nessa questão de tolerância, eles vão ficando mais tolerantes, até na religião. O PEA permite 0 enriquecimento do professor Esses temas não devem estar desvinculados das outras proposições da UNESCO. Você como professor tem ganho e o aluno também tem ganho. A cada tema desse a gente acaba aprofundando um olhar, aumentando a reflexão e isso reflete no aluno. (Escola B, professor)

A gestora da Escola $B$ apresentou maior informação em relação à educação para a formação do cidadão global. Essa escola fez referência a projetos voltados para a formação da consciência global dos alunos e falou da importância de encorajar os alunos a participarem de atividades de intercâmbios com alunos de outros países. Alguns alunos participaram de conferências realizadas pela UNESCO em Paris e no Quait.

Percebe-se por parte dos gestores e professores uma vontade grande em propor uma educação diferenciada e de qualidade, acreditam no potencial da realização de projetos fora da escola e que estes trazem benefícios muito grandes a todos os alunos. Mesmo assim, mostram-se amarrados ao currículo, disciplinas, conteúdos e preparação para o vestibular.

Tanto professores, quanto gestores consideram que o maior desafio do PEA no Brasil é fazer com que as escolas compreendam e realmente coloquem em prática a filosofia do programa. Mais do que trabalhar apenas com projetos isolados na área do ano internacional, educação ambiental, valores ou educação para a paz, as escolas precisam rever sua política e currículo escolar no sentido de incluir, de modo integrado e interdisciplinar, as demais temáticas que fundamentam a prática de uma escola associada da UNESCO.

É preciso, principalmente, não apenas adotar as temáticas sugeridas pela UNESCO, mas discuti-las criticamente a partir da realidade local, regional, nacional e global. A seguir no quadro 2 serão citadas as principais oportunidades, limitações da rede PEA e sugestões feitas através dos relatos dos entrevistados. 
Tabela 2: Rede PEA- oportunidades e limitações

\begin{tabular}{|c|c|c|}
\hline dades & Limitações & Sugestões \\
\hline $\begin{array}{l}\text { - Desperta para um } \\
\text { olhar mais globalizado; } \\
\text { - Divulga os propósitos } \\
\text { da UNESCO; } \\
\text { - Mostra que a escola é } \\
\text { um espaço de } \\
\text { construção de valores; } \\
\text { - Fazer parte da rede é } \\
\text { um diferencial; } \\
\text { - Anos Internacionais } \\
\text { como forma de } \\
\text { unificação e } \\
\text { direcionamento de um } \\
\text { olhar global; } \\
\text { - Difusor de ideias; } \\
\text { - Permite o } \\
\text { enriquecimento do } \\
\text { professor, } \\
\text { - Traz inovação e } \\
\text { reflexão sobre a prática, } \\
\text { - É um referencial de } \\
\text { busca de materiais e } \\
\text { tendências, } \\
\text { - A UNESCO é um } \\
\text { nome forte que traz } \\
\text { credibilidade. }\end{array}$ & $\begin{array}{l}\text { - Comunicação entre } \\
\text { escolas e entre PEA- } \\
\text { escolas; } \\
\text { - Inexistência da rede } \\
\text { enquanto conceito de } \\
\text { rede; } \\
\text { - Muitos materiais não } \\
\text { são traduzidos para o } \\
\text { Português dificultando o } \\
\text { acesso dos professores } \\
\text { e alunos; } \\
\text { - Falta de assistência e } \\
\text { suporte; } \\
\text {-Aproximar } \\
\text { diversidades, } \\
\text { - Poucas escolas } \\
\text { públicas participantes, } \\
\text { - Falta de alternativas } \\
\text { para a escola pública } \\
\text { participar dos encontros }\end{array}$ & $\begin{array}{l}\text { Encontros trimestrais entre escolas } \\
\text { róximas; } \\
\text { Melhora da web site; } \\
\text { Presença dos representantes do PEA ao } \\
\text { ienos uma vez ao ano; } \\
\text { Análise e feedback dos relatórios } \\
\text { nviados apontando melhoras a serem } \\
\text { ealizadas; } \\
\text { Realização de Conferências entre alunos } \\
\text { as quais pudessem debater assuntos de } \\
\text { teresses mundiais, } \\
\text { Propiciar trocas entre escolas de } \\
\text { ealidades bem diversas, } \\
\text { Divulgar o trabalho da UNESCO e PEA, } \\
\text { Criar uma plataforma virtual de fácil } \\
\text { cesso, } \\
\text { Oferecer curso de captação para os } \\
\text { rofessores, } \\
\text { Realização de intercâmbio entre escolas } \\
\text { EA no Brasil e no mundo entre alunos e } \\
\text { rofessores, } \\
\text { Estabelecer parcerias com financiadores } \\
\text { ara que a rede consiga captar verba de } \\
\text { ivestimento em projetos, } \\
\text { Criar jogos entre escolas, como desafios } \\
\text { ara solucionarem problemas do mundo. }\end{array}$ \\
\hline
\end{tabular}

Fonte: Autoria própria.

Todos os entrevistados mostraram-se colaborativos com a proposta, analisando as contribuições que a rede oferece e o que precisa ser melhorado. Reforçam que a ideia de "rede" colabora para um melhor desenvolvimento educacional, no entanto, ela necessita ser dinâmica, de fácil acesso, eficiente e interativa. Melhorar a comunicação interna e externa é um ponto crucial para o fortalecimento das informações, troca de experiências e saberes o que acaba por ampliar e instrumentalizar tanto o professor quanto o aluno. Esta troca é bem evidenciada por FREIRE, (1996, p. 23) na qual afirma que não há docência sem decência, as duas se explicam e seus sujeitos, apesar das diferenças que os conotam, não se reduzem à condição de objeto, um do outro. Quem ensina aprende ao ensinar e quem aprende ensina ao aprender.

Os alunos sugerem ainda um estreitamento maior entre escolas participando de conferências e gincanas interativas. Entendem que uma vivência "extramuro" possibilita aprendizagens mais significativas do que as apenas acadêmicas. Desejam dialogar, debater e participar de discussões a respeito da problemática mundial. Nesse sentido, a rede PEA poderia ser um espaço que dê voz a estes jovens. 


\section{Considerações finais}

Neste estudo de caso comparado fica claro que as práticas educativas na direção da sustentabilidade acontecem ainda de forma pontual e dispersa. Algumas experiências são mais completas e interligadas; outras são pequenas ações que não se articulam com o todo. Cabe destacar que a escola, por si só, não consegue responder por todas as demandas que uma educação para a sustentabilidade exige. É preciso que ela esteja articulada a outras instituições ou organizações.

Dentro do universo desta pesquisa nota-se que, tanto professores quanto gestores, em sua prática, revelam uma percepção fragmentada da problemática ambiental e da crise civilizatória em que nos encontramos o que, entre outras limitações, dificulta o desenvolvimento de uma compreensão crítica do Desenvolvimento Sustentável e inibe a realização de propostas educacionais transformadoras. Validam a importância da formação de cidadãos críticos e responsáveis presente nos relatos e documentos analisados. Apesar disto, ainda thes é difícil compreender a cidadania como participação social, adotando no dia-a-dia da escola o desenvolvimento desta prática.

Os alunos por sua vez, reclamam por participação, envolvem-se em projetos e entendem que estas aprendizagens "extramuro" escolar Ihes foram as mais significativas e inesquecíveis em sua memória estudantil. Os jovens querem participar, atuar e intervir na comunidade que os cercam. Este é um dos caminhos apontados por eles para o desenvolvimento da EDS. Caberá aos gestores das escolas garantirem o espaço dialógico e democrático necessário para que professores, alunos e demais colaboradores possam pensar criticamente, ter voz ativa e participar de todos os processos de decisão e implantação dos projetos adotados pela escola.

Apesar disto, os conceitos que envolvem a EDS ainda são difusos entre os professores e alunos, no entanto todos os entrevistados a remetem a construção de um mundo melhor e necessária. Ainda veem a sustentabilidade como algo intangível e distante de suas realidades.

A UNESCO publica vários materiais de apoio, pesquisas, bem como propõe metas e princípios a serem seguidos para garantir os avanços educacionais alinhados aos ODS. No entanto, percebe-se que, nas escolas analisadas, isto não garante que os estejam utilizando e praticando, o que reforça a influência limitada que a rede oferece em relação à EDS reduzindo assim, o impacto educacional e social que o PEA propõe.

A escola não pode mudar tudo e nem pode mudar a si mesma sozinha. Ela está intimamente ligada à sociedade e a um sistema que a mantém. A escola necessita redescobrir o seu espaço, que é específico numa sociedade de redes e de movimento. É um espaço de relações e de construções.

A rede PEA, por ser uma rede, deveria propor espaços de discussão entre escolas para que buscassem soluções coletivas para a construção de 
uma nova proposta educacional baseada nos pilares da UNESCO e elaborar mecanismos de monitoramento e avaliação dos projetos desenvolvidos.

$\mathrm{Na}$ pesquisa realizada não foi possível perceber a existência de metas estratégicas dentro da rede. Esta se mostra sempre alinhada aos movimentos propostos pela UNESCO no entanto, seria interessante, a realização de uma pesquisa mais aprofundada nesse sentido verificando se há uma ampla avaliação dentro da coordenação nacional sobre os resultados atingidos e caminhos a seguir.

Outro fator a ser considerado na pesquisa é a ambiguidade mostrada entre os princípios que a rede propõe e a realidade. Para um desenvolvimento sustentável, a educação de qualidade e com equidade deve ser garantida a todos para que assim, todas as pessoas consigam exercer seus direitos. No entanto a rede PEA tem, em sua minoria, a associação de escolas públicas. Embora a capacidade e abrangência da rede seja limitada, deveria se buscar caminhos alternativos que pudessem diminuir essa distância.

Uma alternativa sugerida seria estabelecer uma parceria entre as escolas privadas e públicas para o fortalecimento do programa. As escolas privadas são empresas prestadoras de serviços educacionais e como tais devem assumir responsabilidades sociais. Uma forma interessante seria uma escola privada "adotar" uma escola pública o que garantiria uma troca de saberes entre pares diversos, colocando inclusive os alunos, em realidades diferentes, tornando-os protagonistas de suas aprendizagens.

Se um dos principais objetivos do PEA é promover a justiça social, as escolas privadas vinculadas ao Programa devem buscar alternativas para poderem colaborar para melhorar o nível de participação das escolas públicas. O setor privado pode assumir responsabilidades, até como investimento social, assim como as empresas tem investido socialmente em escolas e estabelecendo parcerias, sejam elas financeiras ou formativas, para poderem efetivamente participar em nível de igualdade dentro do PEA.

O PEA deve ser exemplo de inclusão e não de exclusão para que os Objetivos de Desenvolvimento Sustentável (ODS) sejam de fato atingidos.

Para que o programa da UNESCO possa ainda disseminar melhor os seus temas e princípios dentro da realidade estudada, sugere-se que toda comunidade escolar discuta os motivos que a levaram a associar-se, o que isso significa dentro da proposta pedagógica e do currículo escolar. O PEA precisa ser visto como uma possibilidade de repensar e mudar a dinâmica curricular da escola, tornando-a mais próxima da comunidade e de seus problemas sociais e formando cidadãos conscientes e responsáveis.

Resignificar o espaço escolar e as relações com a aprendizagem talvez seja o maior desafio da educação atualmente fazendo com que crianças e jovens, compreendam sua ligação com os problemas que preocupam e afetam a humanidade. Cultivar a comunidade e o sentimento de pertencimento também é outro grande desafio da EDS mostrando ao aluno que ele é 
responsável pelo ambiente em que vive incentivando-o a buscar soluções para os desafios planetários.

Apesar de esse estudo ter se limitado à análise de duas escolas associadas e dos dados terem sido coletados em um curto período de tempo, acredita-se que as informações aqui apresentadas podem servir de base para se repensar o modo como o PEA-UNESCO é entendido e colocado em prática nas escolas parceiras. Porém, recomenda-se a realização de mais estudos na área, incluindo um maior número de escolas e também a participação de pais e outros colaboradores.

\section{Referencias}

ALMEIDA, F. Os desafios da sustentabilidade: uma ruptura urgente. 9a reimpressão. Rio de Janeiro: Elsevier, 2007.

CARLETTO, M.R. et al. Contribuições a uma educação para a sustentabilidade. In: Anais do Congresso Iberoamericano de Ciência, Tecnologia, Sociedad e Innovación (2006). Disponível em:<http://www.oei.es/memoriasctsi/mesa16/m16p04.pdf>. Acesso em: 16 abr. 2015.

DELORS, J. (coord). Os quatro pilares da educação. In: Educação Um Tesouro a Descobrir. Relatório da Comissão internacional sobre Educação para o Século XXI. Brasília, Unesco, 2010

LÜDKE, M.; ANDRÉ, M.E.D.A. Pesquisa em educação: abordagens qualitativas. São Paulo: EPU, 1986.

GUEVARA, A.J.H. et al. (org.). Educação para a era da sustentabilidade. São Paulo: Saint Paul, 2011.

MEC - Ministério da Educação. Relatório Educação para todos no Brasil 2000-2015.

Disponível

em:

$<$ http://portal.mec.gov.br/index.php?option=com docman\&view=download\&alia s=15774-ept-relatorio-06062014\&ltemid=30192> Acesso em: 03 jun. 2015.

MORIN, E. Os sete saberes necessários à educação do futuro. São Paulo: UNESCO/Cortez, 2000.

ONU- Disponível em:<http://nacoesunidas.org/carta/> Acesso em 20 abr. 2015.

PEA - UNESCO. Disponível em: <http://www.peaunesco.com.br/> acesso em 18 abr. 2015.

PEA- UNESCO. Disponível em: <http://www.unesco.org/new/pt/brasilia/aboutthis-office/networks/unesco-associated-schools-in-brazil/\#c154179> acesso em: 21 abr. 2015

PROGRAMA DAS NAÇÕES UNIDAS PARA O DESENVOLVIMENTO - PNUD. Objetivo de desenvolvimento do milênio. PNUD: 2000. Disponível em: $<$ http://www.pnud.org.br/ODM.aspx>. Acesso em: 01 jul. 2015. 
REVISTA

PEA.

Disponível

em: $<$ http://www.peaunesco.com.br/REVISTApea2014R.pdf>. Acesso em: 10 maio 2015.

SETUBAL, M.A. Educação e Sustentabilidade - Princípios e valores para a formação de educadores. São Paulo: Peirópolis, 2015.

STARRATT, R.J. Centering educational administration: cultivating meaning, community, responsibility. New Jersey, USA: Lawrence Erlbaum Associates, publishers. (Tradução de Dr. LynetteShultz e Dr. Ranilce Guimaraes-losif). In: O impacto de se tornar uma escola associada da UNESCO (PEA) no Brasil, 2003

SHULTZ, L. Educating for Global Citizenship: conflicting agendas and understandings. The Alberta Journal of Educational Research. Edmonton, AB: University of Alberta; Faculty of Education. v. 53, n. 3, Fall 2007. p. 248258.

TORRES. R.M. Melhorar a qualidade da educação básica? As estratégias do Banco Mundial. In: TOMMASI, L.; WARDE, M.J.; HADDAD, S. (orgs.) O Banco mundial e as políticas educacionais. São Paulo: Cortez, 1996.

UNICEF/UNESCO. Educação para todos: o compromisso de Dakar. Brasília: UNESCO/CONSED, Ação Educativa, 2001. Disponível em: $<$ http://unesdoc.unesco.org/images/0010/001095/109590por.pdf>. Acesso em: 26 maio 2015.

UNESCO.

Disponível

em: $<$ http://www.unesco.org.br/unesco/sobreaUNESCO/index html/mostra docume nto > Acesso em: 02 jul. 2015.

UNESCO. United Nations Decade of Education for Sustainable Development: (2005-2014) Framework for the International Implementation Scheme", 2003 (UNESCO, 2003, p.2). Disponível em:<http://unesdoc.unesco.org/images/0014/001486/148650E.pdf >. Acesso em: 25 jul. 2015.

UNESCO. Education for Sustainability: From Rio to Johannesburg: Lessons learnt from a decade of commitment-2002. Disponível em: $<$ http://unesdoc.unesco.org/images/0012/001271/127100e.pdf >. Acesso em: 18 ago 2015. 